\title{
Who is the Audience? What the Academic Field of Speech Communication Tells Us About Interpreting Open-Source Messages
}

\author{
William F. Harlow
}

I $\mathrm{n}$ the movie version of The Sum of All Fears, the putative President Nemerov of Russia announced on TV that he had ordered a brutal chemical attack in Chechnya. In reality he had not done so-the attack had instead been ordered by a splinter of his own government. President Nemerov was still willing to claim credit for the attack because he found it more important to be seen as in control of his own government than to deny responsibility for a chemical attack sure to bring international condemnation. This movie clip highlights one of the challenges of analyzing the public statements of high-profile figures: Until the analyst understands the audience with whom a speaker is exchanging messages, it is very difficult to understand the message itself.

Public statements are one way that groups and individual leaders signal their intentions, provide information and disinformation, and achieve other communication ends. While these public statements are only one piece of any given analytic puzzle-some have noted that the "credibility of information obtained from open sources has always been an issue for intelligence and security communities" (Paz 2010, 243) - they are also a readily available data source which can sometimes yield insight and drive policy choices. Additionally, understanding the audience with which a speaker is communicating makes public statements altogether more useful as an analytic tool. The function of this paper is to explain some of the contributions the academic field of Speech Communication can make in understanding and analyzing the public statements of key figures. While my primary focus is on the statements of individuals, many of the same lessons can be applied to groups. I start by providing what Jason Manosevitz (2013) calls the "conceptual framework" for understanding public statements. Having provided this broader reference, I then provide an audience-centered framework for interpreting the speech or other symbolic act.

\section{What is a Rhetorical Situation?}

o understand what a speaker is
doing, one first must understand
the nature of the rhetorical act. When I use the term "rhetoric" here, I do not mean it in any pejorative sense. Rather, I mean it in the sense advanced by Aristotle-a speaker is searching for the available ways to persuade an audience. While a speaker certainly might abuse persuasive tools, searching for them is an act in which we common- 
ly engage. Trying to convince one's teenager, for example, to complete his homework is fundamentally a rhetorical act. More to the point, analysts must interpret the rhetorical acts of speakers as a routine matter to provide an accurate basis for policy judgments somewhere higher up the chain. A rhetorical act is nothing more than what a speaker says-including the context in which it was said, and the audience to which it was addressed. This act can certainly be a speech, but it could also be a video, demonstration, social media post, or any number of other outlets.

A speaker both responds to and creates the rhetorical situation in which he finds himself. Lloyd Bitzer (1968, p. 4) notes "that a particular discourse comes into existence because of some specific condition or situation which invites utterance." In other words, there are real world events and speakers respond to them. Answering Bitzer, Richard Vatz (1973, p. 156) instead argues that, "We learn of facts and events through someone's communicating them to us." That communication changes what the audience knows about and thus may well change what they perceive to be important. From there, Vatz goes on to argue that the act of speaking creates a new reality-at least as that reality is perceive by the audience. For example, if we see a news broadcast about a humanitarian crisis in the Republic of $Z$, we are much more likely to perceive that crisis as important than if we had never heard about it. The act of broadcasting the news changed the reality for the audience-or at least that slice of reality they care about.
In the event, both Bitzer and Vatz have a point. Speakers do respond to real events-for example, a politician is likely to campaign in advance of an election. However, this rhetorical act also creates a new situation. A politician campaigning on some matter of tax policy makes it increasingly likely that some portion of the rest of the campaign will focus on that question, and if elected the leader will be expected (in many countries) to respond to the arguments s/he previously made about what taxes should be. To understand a rhetorical act, the analyst has to consider both things-the situation to which the speaker was responding, as well as the new situation which exists because of the rhetorical act. Understanding that new situation, however, necessarily presupposes understanding who the audience was for the original speech (or video, or social media post, or whatever the utterance was).

\section{Defining the Conceptual Framework}

$\mathrm{S}$ peakers respond to real situations, and in so doing create new situations. This raises two further issues: The broader conceptual framework in which communicative transactions occur, and the notion of what constitutes an audience. I begin by defining the broad context in which messages are exchanged. Manosevitz (2013) noted that issues broader than whichever structured analytic technique (SAT) the analyst employs necessarily color how that technique is understood. In the case of a public statement, the concep- 
tual framework involves a background understanding of the process of human communication.

Too many assume that communication is unidirectional-a speaker makes a statement and sends it to a receiver. Shannon (1948) developed one of the earlier formal models of communication. Now referred to as the "hypodermic model," it asserts that a speaker is somehow capable to delivering a message directly to an audience which is then absorbed as intended. While this is true in part-speakers do in fact deliver messages to audiences-it ignores the role feedback plays in the communication process and assumes that audiences receive the messages as intended. It also assumes that there is a single speaker delivering a message to a single audience. A report from Arizona State University (Goodall et. al., 2006) notes that this one-way model of influence is outdated. Harlow (2010) argued that the hypodermic model also causes an analytic error: When we assume communication to be unidirectional, we frequently assume that any message we hear was intended for us. This implies a limited understanding of audiencethe fact that someone heard a message, and even the fact that the speaker stated that the message was for them, does not mean that person was the intended audience.

Schramm (1954) advanced this model with his notion of feedback. Sometimes called the interactional model of communication, Schramm's work is premised on the assumption that after an audience has received a message, they are apt to send feedback to the speaker. This was an important advance from the hypodermic model, because it cemented the idea that audiences do not simply receive an act of communication the way a patient receives an injection from a physician. Rather, the audience is an active part of the conversation who is going to do something with the message received. However, the interactional model still suffers from the idea that there is a single audience that is readily identifiable and that this audience patiently waits its turn to provide feedback to the speaker. It also lends itself to the notion that the audience's response to the speaker is readily identifiable. While this model was an important advance, it promotes the idea that communication is based on turn-taking behavior which very rarely happens in the real world.

The transactional model of communication (National Communication Association, 2014) builds on the work of Schramm and others to add the idea that both sender and receiver are simultaneously encoding and decoding messages. This means that rather than patiently waiting and taking turns while the first party is talking, the second party is constantly giving feedback and sending messages of his or her own. In the case of two people who are in the same room, this is reasonably clear to see-parties might gesture, interrupt, pay attention, look away, or exhibit any number of other behaviors in order to signal approval, disapproval, or understanding of a message. With public speaking the same basic premise applies-audiences will clap, or get up and leave, or throw rotten fruit. However, 
that applies only to those members of the audience who are in the same physical space at the same time as the speaker. Mediated messages mean that the feedback will take other forms-voting, telling friends, quiet acceptance, and sometimes rioting in the public square. However, there will always be some sort of response from the audience-at least from whichever audience is most important to the speaker.

In addition to the basic flow of messages, there are additional elements to each of these models of communication. Noise, also known as interference, is the notion that something may impede transmission or reception of a message. Physically blocking a broadcasting signal would be an example of noise, as would the fact that a member of the audience was distracted and not paying attention. The channel is the route through which a message is sent, and speakers encode the messages which audiences decode. These elements of the communication process are discussed extensively by other scholars. However, the purpose of this article is not to provide an overarching understanding of communication theory. Rather, this first section is designed to introduce a basic conceptual framework for understanding a communicative transaction.

In terms of conceptual frameworks for understanding public messages-or any other communicative transaction, for that matter-analysts and policy makers have to keep in mind that speakers both respond to and create the situation in which they are speaking, and communication is a constant back and forth flow between speaker and audiences. To interpret a message, an analyst must be able to determine who the relevant audiences were in order to determine how they were likely to perceive the message and, thus, to determine what the speaker was trying to accomplish. The next section of this article provides some insights from the academic discipline of Speech Communication which may help determine who the relevant audiences are.

\section{An Audience-Centered Framework for Understanding Public Statements}

B efore determining who the relevant audience is or who the relevant audiences are, one must remember that there is almost always more than one audience for any public act. When President Biden delivers his State of the Union message, for example, he is certainly speaking to members of Congress. He is simultaneously speaking to justices of the Supreme Court, voters, the politically disengaged, foreign leaders, and anyone with a television set. While a set piece speech from the president might be an extreme example, it still illustrates the point-acts which can be seen or heard by more than one audience probably are. The key is determining which audience is most important to the speaker.

Campbell and Huxman (2009) identified four potential audiences which any speaker might address. The first is the empirical audience, or "all those exposed to the rhetorical act" (Campbell and Huxman, p. 192). Anyone who hears the message is thus a 
member of the empirical audience, and that extends well beyond those in physical proximity with the speaker. Messages which are printed or recorded can have an empirical audience miles away or years after transmission of the message. The simple fact that a reader or listener has received a message does not mean that it was intended for him.

The target audience are those members of the empirical audience with characteristics desired by the speaker. Campbell and Huxman note that in advertising, a target audience is one with needs which the advertised product can fill. For example, a jihadist web site might target audience members of a sympathetic community who would be receptive to the message displayed. However, not all members of this target audience would be in a position to act on the message transmitted. In advertising, some might not have the money to purchase the product. For a terror group, those reading its web site might value other things more than the message received or might lack the physical capacity to act in the manner promoted. Those who have the capacity to do as the speaker wishes are agents of change. Much as the target audience is a subset of the empirical audience, the agents of change are a subset of the target audience.

That does not mean, of course, that the larger target audience is irrelevant. The inability to act as desired right now does not mean that the recipient will never be able to act as desired by the speaker. Also, the agents of change are not necessarily those sympathetic to whatever message is being promot- ed. Rather, they possess characteristics desired by the speaker. As such, a high-level analyst in a rival intelligence agency could be the agent of change for a disinformation campaign - s/he would be in position to direct resources, and it might well be the intent of the speaker that those resources be directed in an altogether different direction. The key isn't sympathy with the messageit is the ability to act as desired by the speaker.

The final type of audience identified by Campbell and Huxman is the created audience. This involves the audience imagining itself in a role described by the speaker. Speakers will quite frequently describe scenarios more desirable than reality-if one was trying to sell cigarettes, for example, one might create for the audience an image of a rugged cowboy riding a horse while free of any cumbersome entanglements. While few have had that reality created for them by smoking, many have become part of the created audience who imagined themselves in such a position.

The first analytic task in interpreting a discursive act, then, is to determine to whom the speaker was sending a message. While the imagined audience tells something of whom the speaker is targeting, the first three types of audiences are often easier to identify. Since they are actual people living in the present, they are potential current targets of the communication. These three audiences-empirical, target, and agents of change-can essentially be treated as a series of concentric circles. While the analytic task is to get to the innermost circle, failure to consider 
membership in the outer circles may lead the analyst to misidentify who the agents of change really are.

While necessary, identifying the target audience for a message is insufficient to truly understanding the message. The second step in the process should be looking at the messages which various audiences are returning to the original speaker. Most of these responses will not be so neatly coded as public speeches video-taped and sent as a formal reply to the original. Rather, one has to consider who might have been expected to respond and analyze what they said, or did, or even what they didn't say in response. There are several questions the analyst can ask to help determine who the target audiences and agents of change were. To follow the example through, I will answer each question for the fictional President Nemerov as his speeches are being analyzed by an opposition force. The first of those questions returns to the concept of noise.

Was the rhetorical act simply an instance of created noise? Not every rhetorical act will have a target audience who is supposed to digest and correctly interpret a message. As discussed earlier, noise is anything which impedes the transmission or reception of a message. Sometimes, speakers create their own noise in order to divert attention from some other item. One potential analytic tool to determine whether a rhetorical act is created noise is to determine who would have been offended by it. Very few pieces of public rhetoric will be completely without opposition. If nobody-or at least no identifiable audi- ence-objects to a message, it may well be an act of created noise which wasn't created for any specific audience. This wasn't the case for the fictional President Nemerov-there was a very clear opposition to his speech, as is wont to happen when one announces the launching of chemical weapons. Assuming, however, that the speech (or video, or pamphlet, or whatever the rhetorical act happens to be) is not simply such a smokescreen, there are several other questions the analyst can ask to help determine who the target audience was.

Who might respond positively to the message? This is the created audience, and it isn't an either/or test. Saying one party might respond positively to a message does not preclude another party from also so doing. These would be the created audiences discussed earlier-they can see themselves benefitting and are thus more likely to respond. If an analyst can identify some group or groups who might respond positively to a message, then that is an excellent place to start looking for target audiences. Someone might have been happy about the attack. It also wouldn't have been-at least not demonstrably-any member of Nemerov's own government. Had such a person appeared, they would have been worth analytic time to determine whether they were the target audience for his speech. However, the empirical statement-the thing which was actually said-is not the only statement the speaker might have made.

What would the reaction have been to any other message? To ascertain who the audience was for a rhetorical act, one has to imagine the other op- 
tions available to the speaker. Using the example here, President Nemerov also had the option of saying he was not responsible for the attack on Chechnya. Denying responsibility would have, at least temporarily, ameliorated his international problems. It also would have helped him at a later point in the movie when a bomb exploded in the U.S. However, it would have opened him to a host of attacks from those who knew he did not control his own forces and was ignorant concerning a large-scale event in his own country. Even if someone is clearly happy with a statement, the analytic task is to avoid confirmation bias. To do that, the analyst should ask what the reaction would have been to any other statement that would have been made. Those counterfactual statements would at least suggest another possible audience. Had President Nemerov made any other statement there would have been a coup in his nearterm future.

In this particular case, it is also worth returning to the first question in this list-what if the statement is nothing but noise intended as a form of misdirection? There was certainly an element of misdirection here. However, there were also parties who were clearly unhappy with the statement made by President Nemerov. That meant that the fictional president very clearly was sending a message-it was just a message to a different group of people. The Russian president also had an altogether different option from sending a different message than the one he did-he might have elected to say nothing at all.
Was it necessary for the speaker to create this rhetorical act? The International Encyclopedia of Strategic Communication (Harlow, 2018) defines strategic silence as "the choice of an empowered actor who remains silent in an attempt to advance a strategic interest." An empowered actor is one who would normally be expected to have something to say on a subject, and silence "is relative to what might be said" (Brummett, 1980). In other words, a president who has a statement on military matters delivered by his Secretary of Defense would be practicing a relative silence-it is a subject on which the president would be fully empowered to speak, but having the SecDef give the statement would give it less weight than it would have coming directly from the president. Harlow (2011) gives an example of strategic silence in studying the failure of President George H.W. Bush to condemn apartheid in South Africa. He received harsh domestic condemnation for not so doing. Archival documents reveal that Bush considered giving precisely such a speech, which would have shifted focus to a different audience-his domestic critics. However, Bush elected not to give the speech in order to give President de Klerk and his opponents in the ANC time to reach a peaceful political settlement without being seen as giving in to the demands of the U.S. president. The choice to practice a strategic silence was because he viewed those groups as his more relevant audience.

In assessing who the target audience is, then, one part of the analytic task is to determine whether the speak- 
er had a strategic option of remaining silent. Strategic silence sends signals to audiences as surely as does speech, so the act of speech frequently implies a shift in who the speaker views as the target audience. Had President Nemerov elected to not speak in our movie example, that would have been an appeal to some audience somewhereeven if it was only a play for time from that audience. His decision to say that he ordered the chemical weapons attack instead signaled that he viewed the relevant audience as the parties who would have taken advantage of his failure to control his own country.

\section{Figuring Out Who the Audience Is}

$O$ peakers both respond to and create situations. In the movie, someone had attacked Chechnya and someone asked President Nemerov about it. That was a real situation which called for a response from him. However, in the act of answering the question Nemerov created a new reality-one in which he was seen as culpable for a heinous act and was presumed responsible for another act later in the movie. This happened in a context in which there was a constant flow of messages between $\mathrm{Ne}$ merov and other parties; figuring out what those message meant implied analyzing the audience for whom they were intended. Unfortunately, the real-world analytic task is significantly more complicated since it lacks a movie's plot line to conveniently follow.

While that analytic task is complicated, it is also vital. Policy makers can't make sound judgments if they don't know why significant figures have said what they did, and that can't be answered without understanding who the audience was in the first place. Identifying audiences is one of the central strengths of the academic discipline of Speech Communication. While identifying the target audience isn't foolproof, without at least attempting to identify the audience you have no hope of understanding the message. In this essay, I have attempted to present at least the initial outlines of a framework for identifying who those audiences might be. When you are trying to understand why somebody said something, try to identify to whom they are talking-and remember that your having heard the message doesn't mean it was intended for you.

William F Harlow, Ph.D., is Professor and Chair of the Department of Communication at The University of Texas Permian Basin (UTPB). He earned a Ph.D. in Speech Communication from Texas A\&M in 2002, and later that year he started his professional career at Texas Tech. In 2003, he became a Foreign Service Officer and served with the State Department in Mexico City and Abuja, Nigeria. In 2007 he left the Foreign Service to serve as Secretary of the International Boundary and Water Commission (U.S.-Mexico). He also taught 
graduate-level intelligence analysis courses at American Public University from 2007-2010. In 2008, Dr. Harlow began a full time faculty career at UTPB, where he served as Dean of Undergraduate Success from 2012-2019. When he is not teaching or spending time with his wife and kids, Dr. Harlow coaches Little League baseball. He would be delighted to pursue joint work on future scholarly projects. The best way to reach him is via email to harlow_w@utpb.edu.

\section{References}

Bitzer, Lloyd. 1968. “The Rhetorical Situation.” Philosophy \& Rhetoric 1, no. 1 (January): 1-14.

Brummett, Barry. 1980. “Towards a Theory of Silence as a Political Strategy.” Quarterly Journal of Speech 66. 289-303.

Campbell, Karlyn K, and Susan Schultz Huxman. 2009. The Rhetorical Act: Thinking, Speaking, and Writing Critically $4^{\text {th }}$ ed. (United States of America: Wadsworth Cengage Learning).

Goodall, Bud, Angela Trethewey, and Kelly McDonald. 2006. Strategic Ambiguity, Communication, and Public Diplomacy in an Uncertain World (Arizona State University Consortium for Strategic Communication, June 21), 1-14.

Harlow, William F. 2010. "Audience-Centered VNSA Strategic Communication." In Protecting the Homeland from International and Domestic Terrorism Threats: Current Multi-Disciplinary Perspectives on Root Causes, the Role of Ideology, and Programs for Counter-radicalization and Disengagement, edited by Laurie Fenstermacher et al., 237-242. Air Force Research Laboratory.

Harlow, William F. 2011. “The Triumph of Silence: President George H.W. Bush's Refusal to Denounce Apartheid in South Africa." Rhetoric and Public Affairs 14. 45-68.

Harlow, William F. 2018. "Strategic Silence." In The International Encyclopedia of Strategic Communication, edited by Robert L. Heath and Winni Johansen. John Wiley \& Sons.

Manosevitz, Jason U. 2013. "Needed: More Thinking about Conceptual Frameworks for Analysis-The Case of Influence," Studies in Intelligence 57. 15-22.

National Communication Association, "Transactional Model of Communication," 
https://www.natcom.org/transactionalmodel/. Accessed August 27, 2014.

Paz, Reuven. 2010. "VNSA Strategic Communications: Reading Their Lips: The Credibility of Militant Jihadi Web Sites as 'Soft Power' in the War of the Minds." In Protecting the Homeland from International and Domestic Terrorism Threats: Current Multi-Disciplinary Perspectives on Root Causes, the Role of Ideology, and Programs for Counter-radicalization and Disengagement, edited by Laurie Fenstermacher et al., 243-254. Air Force Research Laboratory.

Schramm, Wilbur. 1954. "How Communication Works." In The Process and Effects of Mass Communication, edited by Wilbur Schramm, 3-26. (Urbana: University of Illinois Press).

Shannon, Claude. 1948. "A Mathematical Theory of Communication." Bell System Technical Journal 27 (July): 379-423.

Vatz, Richard E. 1973. “The Myth of the Rhetorical Situation." Philosophy \& Rhetoric 6, no. 3 (Summer): 154-161. 